\title{
Torasik cerrahi sonrası postoperatif pulmoner komplikasyonların önlenmesinde İnsentif spirometre ve Continuous Positive Airway Pressure (CPAP)'ın karşılaştırılması*
}

\section{Comparison of Incentive spirometry and Continuous Positive Airway Pressure (CPAP) on the prevention of postoperative pulmonary complications after thoracic surgery}

\begin{abstract}
Alis KOSTANO $\breve{G} L U^{1}$ Ela TARAKCI Enver DAYIOĞLU ${ }^{1}$ Sabriye DEMIRC $\dot{I}^{3}$

${ }^{1}$ İstanbul Üniversitesi Istanbul Tip Fakültesi, Kalp Damar Cerrahisi Anabilim Dall, İstanbul, Türkiye
\end{abstract}

${ }^{2}$ İstanbul Üniversitesi Sağllk Bilimleri Fakültesi, Fizyoterapi ve Rehabilitasyon Bölümü, İstanbul, Türkiye

${ }^{3}$ İstanbul Üniversitesi Cerrahpaşa Tip Fakültesi, Iç Hastalıkları Anabilim Dal, İstanbul, Türkiye

Yazışma adresi/ Coresspondence Alis Kostanoğlu, ${ }^{1}$ Istanbul Üniversitesi Istanbul Tip Fakültesi, Kalp Damar Cerrahisi Anabilim Dall, İstanbul, Türkiye aliskostanoglu@yahoo.co $\mathrm{m}$

Geliş Tarihi /Recevied 01/07/2014

Kabul Tarihi/Accepted 03/09/2014

HSP 2014 1(2): 57-67
Özet:

Amaç: Torasik cerrahi geçiren hastalarda İnsentif spirometre ve devamlı pozitif havayolu basınc1- Continuous Positive Airway Pressure maskesinin postoperatif pulmoner komplikasyonlar üzerine etkisinin araştırılması. Gereç ve Yöntemler: Çalışmaya torasik cerrahi geçiren hemodinamik açıdan stabil, yaşları 16-75 arasında değişen 14'ü kadın, 16'sı erkek toplam 30 hasta dahil edildi. Hastalar ekstübasyonu takiben randomize olarak iki gruba ayrıld1. 1. grupla "İnsentif Spirometre" çalışmaları, 2. grupla ise "CPAP uygulaması" yapıldı. Tüm olguların postoperatif birinci ve dokuzuncu günde arter kan gazları, solunum fonksiyon testleri ve akciğer radyolojik incelemesi yapıldı ve sonuçlar karşılaştırıldı. Bulgular: Olgularla çalışmaya başlandıktan sonra postoperatif birinci ve dokuzuncu günde yapılan arter kan gazı sonuçları gruplar arası farklı bulunmadı (p>0.05) Her iki gruptaki hastaların Zorlu Vital Kapasite-Forced Vital Capacity (FVC), birinci saniyede Zorlu Ekspirasyon Volümü-Forced Expiratory Volume 1 second (FEV1), ve Zorlu Eksipratuar Akım-Forced Expiratory Flow (FEF \%25-75) değerlerinde postoperatif dokuzuncu günde preoperatif ölçüm değerlerine göre istatistiksel olarak anlamlı düzeyde azalmalar tespit edildi $(\mathrm{p}<0.001)$. Ancak postoperatif birinci gün ile dokuzuncu gün solunum fonksiyon testleri karşılaştırıldığında ise dokuzuncu günde her iki gurupta da anlamlı düzelmeler başladı $(\mathrm{p}<0.001)$. Solunum fonksiyon testlerinin tüm parametrelerinde gözlenen bu düzelmenin gruplar arasında istatistiksel olarak anlamlı fark oluşturmadığ1 görüldü $\quad(\mathrm{p}>0.05)$. Akciğer radyolojik incelemesinde de tedavi sonras1 iki grup arasında istatistiksel olarak anlamlı fark mevcut değildi $(\mathrm{p}>0.05)$. Sonuç: Torasik cerrahi geçiren hastalarda solunum performansını geliştirmek için mekanik fizyoterapi teknikleri etkilidir. İnsentif Spirometre ve CPAP uygulamasının pulmoner komplikasyonları önleme açısından birbirlerine üstünlükleri yoktur.

Anahtar Kelimeler: Toraks cerrahisi; insentif spirometre; Continuous positive airway pressure; solunum fonksiyon testleri; fizyoterapi

*Bilim Uzmanlığı Tezi 


\begin{abstract}
Abstrac
Aim: Investigating effects of Incentive Spirometry and Continuous Positive Airway Pressure (CPAP) masks on postoperative pulmonary complications in patients who were undergone thoracicsurgery. Material and Methods: The study enrolled totally 30 patients, including 14 female and 16 male patients, who were hemodynamically stable following thoracic surgery. Following the extubation, patients were randomly divided into two groups. "Incentive Spirometry" studies were performed with group 1, while "CPAP" studies were performed with group 2. For all cases, arterial blood gases analysis, respiratory functions tests and pulmonary X-ray examinations were performed at postoperative first and ninth days. Results: Following the onset of study, no difference could be found in arterial blood gases results performed at post-operative first and ninth days $(\mathrm{p}>0.05)$. In both groups, statistically significant decrease in Forced Vital Capacity (FVC), Forced Expiratory Volume in one second (FEV1) and Forced Expiratory Flow (FEF \%25-75) values measured at post-operative ninth days was found in comparison with pre-operative measurement values $(p<0.001)$. However, pulmonary function tests were compared postoperative first the ninth days and significant improvements in both groups began ninth day $(\mathrm{p}<0.001)$. It was observed that the improvement found in all parameters of respiratory function tests did not have statistically significant differences $(p>0.05)$. In the pulmonary X-ray examination, there was not statistically significant difference between two groups following the therapy ( $>>0.05$ ). Conclusion: Mechanic physiotherapy techniques are efficient for improving respiratory performance in patients who are undergoing thoracic surgery. Incentive Spirometry and CPAP are not superior to each other on preventing pulmonary complications.
\end{abstract}

Key words: Thoracic surgery; Incentive Spirometry; Positive Airway Pressure; pulmonary function tests; physiotherapy

\title{
Giriş ve Amaç
}

Major operasyonlardan sonra ortaya çıkan komplikasyonların büyük bir kısmını pulmoner komplikasyonların oluşturduğu bilinmektedir. ${ }^{1-3}$ Bunun sebebi, anestezinin neden olduğu solunum kasları disfonksiyonu ve göğüs duvarı mekaniklerinin bozulması sonucunda akciğer hacimlerinde gerçekleşen değişimlerdir.

Torasik cerrahi sonrasında, anestezinin etkilerine ilave olarak, vertikal insizyonlar ağrıya neden olarak, mobilizasyonu kısıtladığı için postoperatif dönemde komplikasyonlara sebep olabilmektedir. ${ }^{4-9}$ Bunlar öncelikle atelektazi, pnömoni, plevral effüzyon olarak siralanabilir. $\mathrm{Bu}$ komplikasyonlar postoperatif morbidite ve mortalitenin en önemli nedenleridir.

Torasik cerrahi işlemlerinden sonra postoperatif pulmoner komplikasyon görülme sıklığı (\%19-59), üst abdominal cerrahi (\%16-17) veya alt abdominal cerrahiye (\% 0-5) oranla daha yüksektir. ${ }^{10,11}$ Oranlar cerrahinin yerine, risk faktörlerinin varlığına ve bir postoperatif pulmoner komplikasyonu belirlemede kullanılan kriterlere göre değişir. ${ }^{12}$ Postoperatif pulmoner komplikasyonlar hastaların hastanede kalış sürelerini uzatır. $\mathrm{Bu}$ sebeple komplikasyon gelişme riskini azaltmak için bazı önlemler alınabilir. Birçok araştırmacı preoperatif ve postoperatif dönemde değişik fizyoterapi teknikleri uygulayarak komplikasyonların gelişme hızını ve sıklığını azaltmışlardır. Bu fizyoterapi teknikleri solunum egzersizleri, İnsentif Spirometre (ISS), Devamlı pozitif havayolu basinc1Continuous Positive Airway Pressure (CPAP) uygulaması, ekspiratuar manevralar, intermittan pozitif basınçlı solunum (IPPB), aktif solunum teknikleri döngüsü olarak sıralanabilir. Bu tekniklerin birbirlerine olan üstünlükleri ise kontrollü çalışmalarla farklı 
biçimlerde gösterilmiştir. ${ }^{13-15}$

Çalışmamızda göğüs fizyoterapi uygulamalarında farklı iki metod olan İS ve CPAP'1 karşılaştırmayı tercih ettik. Bu iki teknik; arteryel kan gazları, solunum fonksiyon testleri ve akciğer radyografileri ile değerlendirilerek pulmoner komplikasyonların önlenmesi bakımından karşılaştıııldı.

\section{Gereç ve Yöntemler}

Çalışma torasik (pulmoner cerrahi ve kalp cerrahisi) operasyon geçiren hemodinamik açıdan stabil 30 hastadan yazılı onayları alınarak gerçekleştirildi.

Araştırmamız etik kurul onay alındıktan sonra Helsinki Deklorasyonu'na uygun olarak yürütüldü.

\section{Çalışma Grubu}

Yaşları 16-75 arasında değişen, hemodinamik açıdan stabil, koopere olan ve preoperatif dönemde Kronik Obstrüktif Akciğer Hastalığı (KOAH) tanısı almamış olan 14'ü kadın, 16's1 erkek toplam 30 hasta çalışmaya dahil edildi. Hastalar randomize yöntemle iki gruba ayrıldı. Randomizasyon cerrahiden hemen önce hastalar tarafından seçilen kapalı zarf yöntemi ile yapıldı. Hastaların 5 tanesi lobektomi, 5 tanesi mitral valv replasmanı (MVR), 3 tanesi atrial septal defekt (ASD), 3 tanesi aort valv replasmanı (AVR), 11 tanesi koroner arter bypass greft (KABG), 1 tanesi pnömonektomi, 2 tanesi ise hem AVR hem de MVR operasyonu geçirmişti. KABG operasyonu geçiren ve hemodinamisi bozuk olan iki hasta çalışmaya dahil edilmedi. CPAP uygulanan guruptan pnömonektomi geçiren bir hasta postoperatif 3. gün ex olduğu için çalışma dışı kaldı.

\section{Kullanılan Değerlendirmeler}

Tüm değerlendirmeler ilk olarak preoperatif dönemde, ardından postoperatif dönemde pulmoner komplikasyon riskini engellemek için yapılan fizyoterapi uygulamalarını takiben yapild1.

Demografik özellikler: Olguların yaş, vücut ağırlığı ve boy uzunlukları kaydedildi.

Solunum fonksiyon testleri: Respirodyne-II aleti kullanılarak yapıld1. Zorlu Vital Kapasite (Forced vital capacity- FVC), birinci saniyede zorlu ekspirasyon volümü (Forced expiratory volum-FEV $\mathrm{F}_{1}$, 1. saniyede zorlu ekspiratuar volümün zorlu vital kapasiteye oranı (FEV 1 /FVC), zorlu eksipratuar akım (Forced expiratory flow-FEF \%25-75) orta değeri parametrelerine bakild1. Testler hastalar yatakta uzun oturma pozisyonunda ve yatak başları 60 derece elevasyonda iken gerçekleştirildi. Test uygun dinlenme aralığı verilerek üç defa tekrarlandı. Bu üç değerden en yüksek olan seçildi.

Arter kan gazı ölçümü: ABL 500 cihazı kullanılarak yapıldı. Arter kan gazları $\mathrm{PaO}_{2}$ (parsiyel oksiyen basınc1), $\mathrm{PaCO}_{2}$ (parsiyel karbondioksit basınc1) ve Oksijen Satürasyonu parametrelerine bakıld1. Akciğer Radyografik İncelemeleri: Akciğer grafileri yatakta uzun oturma pozisyonunda ve yatak başları 60 derece elevasyonda iken çekildi. Akciğer radyografileri, atelektazi ve plevral efüzyon riski açısından değerlendirmeye alındı. 


\section{Uygulamalar}

Torasik operasyon geçiren 30 hasta ekstübasyonu takiben randomize olarak iki gruba ayrıldı. 15 kişilik 1. grupla "İS” çalışmaları, 15 kişilik 2. grupla ise "CPAP” çalışmaları yapıldı. Her iki gruptaki hastalara mekanik fizyoterapi uygulamalarından sonra öksürük egzersizleri yaptırıldı. Öksürme egzersizleri için hasta uzun oturma pozisyonunda, yatak baş1 60-90 derece elevasyonda ve insizyon yeri bir yastıkla desteklenerek pozisyonlandı. Hastadan derin bir inspiryumu takiben öne doğru eğilmesi ve hızla ekspiryum yapması ardından öksürmesi istendi. ${ }^{14}$ IS grubundaki hastalar postoperatif 1 . gün yatak baş1 $45^{\circ}$ yükseltilerek ve uzun oturma pozisyonunda her saat baş1 5 dakika süreyle, günde toplam 1 saat insentif spirometre ile çalıştırıldı. İnsentif spirometre hastalara geniş bir inspiratuar efor yapması konusunda olanak sağlar ve bu sayede postoperatif dönemde solunum kaslarını kuvvetlendirerek, istemli nefes alı-vermeyi arttırarak ve öksürme refleksini uyararak pulmoner komplikasyonların oluşma riskini önler. ${ }^{14} \mathrm{CPAP}$ grubundaki hastalar ise postoperatif birinci gün yatak baş $145^{\circ}$ yükseltilerek ve uzun oturma pozisyonunda her saat başı 5 dakika süreyle günde toplam 1 saat $\mathrm{CPAP}$ ile çalıştırıldı. CPAP basıncı $5 \mathrm{cmH}_{2} \mathrm{O}$ idi. CPAP arteriyal kan oksijenasyonunu arttırır, nefes alıp verme işlemini kontrol ederek dispneyi azaltır ve pulmoner komplikasyonların oluşma riskini önler. ${ }^{15}$ Her iki gruptaki hastalar ikinci günden dokuzuncu güne kadar iki saatte bir çalışmaya alındı, hastalarla toplam dokuz gün çalışıldı.

Tüm olguların postoperatif birinci ve dokuzuncu günde arter kan gazları ve akciğer radyolojik incelemesi, postoperatif dokuzuncu günde ise solunum fonksiyon testleri yapıldı ve sonuçlar karşılaştırıldı.

\section{İstatistiksel Analizler}

Çalışmanın veri analizinde SPSS istatistik programının 11.5 versiyonu kullanıldı. İki grubun ameliyat öncesi ve sonrası solunum fonksiyonları ve arter kan gazlarındaki değişimlerin karşılaştırılmasında Mann-Whitney U testi, birinci ve dokuzuncu günlerdeki değişim ise Covaryans testi ile yapıldı. Akciğer radyografilerinin karşılaştırılmasında kikare testi kullanıldı.

\section{Bulgular}

Torasik operasyonlardan sonra postoperatif pulmoner komplikasyonların oluşmasını önlemek amacıyla yaptığımız bu çalışmada solunum fonksiyon testleri, arter kan gazları ve göğüs radyolojik incelemeleri kriter olarak kullanıldı. Olguların yaş, vücut ağırlığı, boy gibi bazı demografik bilgileri Tablo 1'de verilmiştir. Her iki grup arasında demografik özellikler açısından istatistiksel olarak farklılık bulunmadı. Hastaların ortalama yoğun bakım kalış süresi iki gün (1-7), hastane kalış süresi ortalama sekiz gün (7-19) olarak kaydedildi.

Solunum Fonksiyon Testleri: İS ve CPAP grubundaki hastaların preoperatif solunum fonksiyon testi sonuçları Tablo 2'de özetlendi. FVC, FEV 1 , FEV $/$ / FVC, FEF 25-75 değerleri ve $\mathrm{PaO}_{2}, \mathrm{PaCO}_{2}$, Oksijen satürasyonu değerlerinin hiçbirinde preoperatif dönemde gruplar arası istatistiksel fark yoktu. 
Tablo 1. Hastaların Demografik Özellikleri

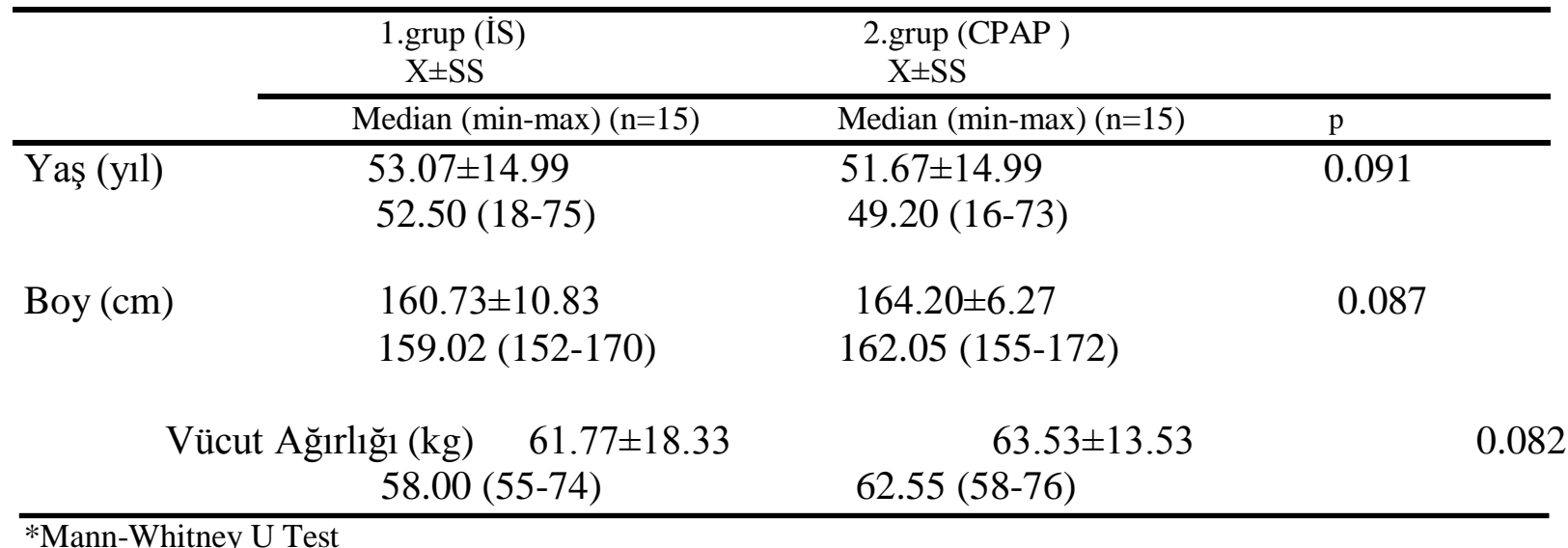

Tablo 2. 1. Grup ve 2. Grup Hastaların Preoperatif Dönem Solunum Fonksiyon Testi ve Arter Kan Gazları Değerlerinin Karşılaştırılması

\begin{tabular}{llll}
\hline & \multicolumn{1}{c}{$\begin{array}{c}\text { 1.grup (IS) } \\
\mathrm{X} \pm \mathrm{SS}(\mathrm{n}=15)\end{array}$} & \multicolumn{1}{c}{$2 . \operatorname{\mathrm {X}} \pm \mathrm{SS}(\mathrm{n}=15)$} & $\mathrm{p}$ \\
\hline $\mathrm{FVC}(\mathrm{lt})$ & $2.83 \pm 1.04$ & $3.24 \pm 1.09$ & 0.077 \\
$\mathrm{FEV}_{1}(\mathrm{lt})$ & $2.25 \pm 0.89$ & $2.64 \pm 1.02$ & 0.086 \\
$\mathrm{FEV}_{1} / \mathrm{FVC}(\%)$ & $78.69 \pm 11.22$ & $79.09 \pm 11.50$ & 0.094 \\
$\mathrm{FEF}_{25-75}(\mathrm{lt})$ & $2.17 \pm 1.29$ & $2.97 \pm 1.55$ & 0.187 \\
$\mathrm{PaO}_{2}(\mathrm{mmHg})$ & $85.81 \pm 17.06$ & $92.36 \pm 9.85$ & 0.084 \\
$\mathrm{PaCO}_{2}(\mathrm{mmHg})$ & $35.73 \pm 3.34$ & $36.98 \pm 2.07$ & 0.167 \\
$\mathrm{Satürasyon}(\%)^{*}$ & $96.36 \pm 2.60$ & $97.21 \pm 1.17$ & 0.078 \\
\hline
\end{tabular}

*Mann-Whitney U Test

Tablo 3. Preoperatif ve Postoperatif Dokuzuncu Gün Solunum Fonksiyon Testleri Sonuçlarının Karşılaştırması

\begin{tabular}{|c|c|c|c|c|c|c|}
\hline & \multicolumn{2}{|c|}{$\mathrm{X} \pm \mathrm{SS} \_(\mathrm{n}=15)$} & Grup (İS) & \multicolumn{2}{|c|}{$\begin{array}{l}\text { 2.Grup (CPAP ) } \\
\mathrm{X} \pm \mathrm{SS}(\mathrm{n}=15)\end{array}$} & \multirow[b]{2}{*}{$\mathrm{P}$} \\
\hline & Preop. & Postop. 9.Gün & $\mathrm{P}$ & Preop. & Postop.9.Gün & \\
\hline$\overline{\mathrm{FVC}(\mathrm{Lt})}$ & $2.83 \pm 1.04$ & $1.99 \pm 0.98$ & 0.001 & $3.24 \pm 1.09$ & $2.01 \pm 0.69$ & 0.001 \\
\hline $\mathrm{FEV}_{1}(\mathrm{Lt})$ & $2.25 \pm 0.89$ & $1.57 \pm 0.78$ & 0.001 & $2.64 \pm 1.02$ & $1.65 \pm 0.61$ & 0.001 \\
\hline $\mathrm{FEV}_{1} / \mathrm{FVC}(\%)$ & $78.69 \pm 11.22$ & $77.19 \pm 9.37$ & 0.078 & $79.09 \pm 11.50$ & $80.6 \pm 8.16$ & 0.073 \\
\hline $\mathrm{FEF}_{\% 25-75}(\mathrm{Lt})$ & $2.17 \pm 1.29$ & $1.38 \pm .0 .79$ & 0.001 & $2.97 \pm 1.55$ & $1.73 \pm 0.97$ & 0.001 \\
\hline
\end{tabular}

*Covaryans Testi, Mann-Whitney U Test 
Olgularla çalışmaya başlandıktan sonra postoperatif birinci ve dokuzuncu günde solunum fonksiyon testleri yapıldı. IS ve CPAP grubundaki hastaların preoperatif ve postoperatif dokuzuncu gün solunum fonksiyon testleri sonuçlarının karşılaştırması Tablo 3 'te özetlendi.

Her iki gruptaki hastaların FVC, $\mathrm{FEV}_{1}$ ve $\mathrm{FEF} \% 25-75$ değerlerinde postoperatif dokuzuncu günde preoperatif ölçüm değerlerine göre istatistiksel olarak anlamlı düzeydede idi. Ancak Tablo 4'te gösterildiği gibi postoperatif birinci gün ile postoperatif dokuzuncu gün solunum fonksiyon testleri karşılaştırıldığında postoperatif dokuzuncu günde her iki gurubunda FVC, FEV1 ve FEF \%25-75 değerlerinde anlamlı düzelmeler görüldü ( $p<0,001)$. Solunum fonksiyon testlerinin tüm parametrelerinde gözlenen bu düzelmenin gruplar arasında istatistiksel olarak anlamlı fark göstermediği belirtildi ( $p>0,05)$.

Tablo 4. Postoperatif Birinci ve Dokuzuncu Gün Solunum Fonksiyon Testi Değerlerinin Karşılaştırması

\begin{tabular}{|c|c|c|c|c|c|c|}
\hline & $\begin{array}{c}\text { 1.grup } \\
\mathrm{X} \pm \mathrm{S}\end{array}$ & $\begin{array}{l}\mathrm{p}(\mathrm{IS}) \\
\mathrm{S}(\mathrm{n}=15)\end{array}$ & & $\begin{array}{l}\text { 2.grup (CPA } \\
\qquad \pm \text { SS (n }=\end{array}$ & & \\
\hline & Postop 1.gün & Postop. 9.gün & $\mathrm{p}$ & Postop 1.gün & Postop. 9.gün & $p$ \\
\hline FVC (lt) & $1.65 \pm 0.79$ & $1.99 \pm 0.98$ & 0.001 & $1.62 \pm 0.61$ & $2.01 \pm 0.69$ & 0.001 \\
\hline $\mathrm{FEV}_{1}(\mathrm{lt})$ & $1.27 \pm 0.61$ & $1.57 \pm 0.78$ & 0.001 & $1.31 \pm 0.5$ & $1.65 \pm 0.61$ & 0.001 \\
\hline $\mathrm{FEV}_{1} / \mathrm{FVC}(\%)$ & $77.39 \pm 6.48$ & $77.19 \pm 9.37$ & 0.089 & $80.15 \pm 8.85$ & $80.6 \pm 8.16$ & 0.091 \\
\hline $\mathrm{FEF}_{\% 25-75}$ (lt) & $1.06 \pm 0.65$ & $1.38 \pm .0 .79$ & 0.001 & $1.36 \pm 0.70$ & $1.73 \pm 0.97$ & 0.001 \\
\hline
\end{tabular}

*Mann-Whitney U Test

Arter Kan Gazları: Olgularla çalışmaya başlandıktan sonra postoperatif birinci ve dokuzuncu günde arter kan gazı değerleri tayin edildi. Ölçüm sonuçları İS ve CPAP grubundaki hastalar için Tablo 5'te özetlendi. Arter kan gazı değerleri açısından gruplar arası farklılık bulunmadi.

Tablo 5. Postoperatif Birinci ve Dokuzuncu Gün Arter Kan Gazı Değerlerinin Karşılaştırması

1.grup (IS) 2.grup (CPAP)

\begin{tabular}{lllllll}
\multicolumn{2}{c}{$\mathbf{X} \pm$ SS } & $(\mathbf{n = 1 5})$ & & \multicolumn{2}{c}{$\mathbf{X} \pm \mathbf{S S}(\mathbf{n = 1 5})$} \\
\hline & 1.gün & 9.gün & $\mathbf{p}$ & 1.gün & 9.gün & $\mathbf{p}$ \\
\hline $\mathrm{PaO}_{2}(\mathrm{mmHg})$ & $112.87 \pm 26.79$ & $110.74 \pm 31.96$ & 0.078 & $88.71 \pm 22.95$ & $94.66 \pm 14.57$ & 0.069 \\
$\mathrm{PaCO}_{2}(\mathrm{mmHg})$ & $37.38 \pm 4.96$ & $37.81 \pm 3.84$ & 0.159 & $35.29 \pm 4.20$ & $36.97 \pm 2.87$ & 0.077 \\
Satürasyon (\%) & $98.41 \pm 1.11$ & $97.85 \pm 1.50$ & 0.175 & $96.68 \pm 2.23$ & $96.70 \pm 0.93$ & 0.197
\end{tabular}

*Covaryans Testi, Mann-Whitney U Test

Komplikasyonlar: İS grubundaki hastalarda postoperatif birinci gün, iki hastada lober atelektazi, bir hastada segmental atelektazi, dört hastada ise plevral efüzyon görüldü 
(Tablo 6). CPAP grubundaki hastalarda, postoperatif birinci gün üç hastada lober atelektazi, bir hastada ise plevral efüzyon görüldü. Her iki grup hastada istatistiksel olarak anlamlı fark bulunamadı $(\mathrm{p}>0,05)$. Postoperatif dokuzuncu günde ise İS grubundaki hastaların birinde lober atelektazi, beşinde ise plevral efüzyon görülürken CPAP grubundaki hastalarda ise sadece birinde plevral efüzyon tespit edildi. Komplikasyon bakımından her iki grup arasında istatistiksel olarak anlamlı bir fark bulunamadı $(\mathrm{p}>0,05)$.

Tablo 6. Postoperatif Birinci Ve Dokuzuncu Gün Komplikasyon Sayıları

\begin{tabular}{lcccc}
\hline \multicolumn{2}{c}{ 1.grup (IS) $(\mathrm{n}=15)$} & \multicolumn{2}{c}{ 2.grup (CPAP) $(\mathrm{n}=15)$} \\
\hline & 1.gün & 9.gün & 1.gün & 9.gün \\
\hline Lober Atelektazi (n) & 2 & 1 & 3 & 0 \\
Segmental Atelektazi (n) & 1 & 0 & 0 & 0 \\
Plevral Effüzyon (n) & 4 & 5 & 1 & 1 \\
\hline
\end{tabular}

*Ki-kare

\section{Tartışma}

Torasik cerrahi geçiren hastalarda postoperatif komplikasyonları önlemek için yaptığımız bu çalışmanın sonucunda her iki gruptaki hastaların FVC, FEV 1 ve FEF \%25-75 değerlerinde postoperatif dokuzuncu günde preoperatif ölçüm değerlerine göre istatistiksel olarak anlamlı azalmalar tespit edildi $(\mathrm{p}<0,001)$. Postoperatif birinci gün ile postoperatif dokuzuncu gün solunum fonksiyon testleri karşılaştırıldığında ise postoperatif dokuzuncu günde her iki gurubun da $\mathrm{FVC}, \mathrm{FEV}_{1}$ ve $\mathrm{FEF}$ \%25-75 değerlerinde anlamlı düzelmeler görüldü $(\mathrm{p}<0,001)$. Solunum fonksiyon testlerinin tüm parametrelerinde gözlenen bu düzelmenin gruplar arasında istatistiksel olarak anlamlı fark göstermedi ( $p>0,05)$.

Torasik ve üst abdominal cerrahiden sonra, göğüs kafesi ve diyafragmanın hareketlerinde azalma ve inspirasyon sürecinde belirgin zayıflama gözlenir. Hastaların solunum fonksiyon testleri parametrelerinde özellikle FVC, FEV 1 ve FEF \%25-75 değerlerinde postoperatif dönemde azalmalar beklenir. Bunun sonucunda da pulmoner komplikasyonların görülme oranı oldukça sıktır. Solunum fonksiyon testleri parametrelerinde gerçekleşen bu azalmaları düzeltmek ve ciddi sağlık problemlerine yol açabilen bu komplikasyonların önlenmesi için çeşitli fizyoterapi yöntemlerini kullanan farklı çalışmalar yapılmıştır. ${ }^{8-10}$

Postoperatif pulmoner komplikasyonların önlenmesinde pek çok fizyoterapi yaklaşımı söz konusudur. Bunlar; ekspiratuar manevralar, IPPB, aktif solunum teknikleri döngüsü, İS, CPAP, PEP (Positive Expiratory Pressure) gibi yöntemlerdir. Bu metodların hepsinin ortak amacı, postoperatif dönemde gelişen alveolar kollapsın önlenmesini sağlamaktır. ${ }^{13-15}$

Çalışmamıza dahil edilen hastalarda anamnez, klinik muayene, solunum fonksiyon testleri ve akciğer radyografik değerlendirmesinde, kronik obstruktif akciğer hastalığ başta olmak üzere solunum sistemini kısıtlayan herhangi bir hastalığa rastlanmadı. 
Preoperatif ve postoperatif dönemde birinci ve dokuzuncu günlerde yapılan solunum fonksiyon testleri, arter kan gazları ve akciğer radyografileri ile hastaların klinik durumları objektif bir şekilde değerlendirildi. İki gruba ayrılan hastaların bir yarısına İS, ikinci yarısına ise CPAP uygulayarak hastaların postoperatif pulmoner komplikasyonları, öncelikle atelektazi, pnömoni ve plevral effüzyonu tanımlama bakımından kıyaslanarak değerlendirilmeye çalışıldı.

Postoperatif pulmoner komplikasyonların erken dönemde önlenmesi için intratorasik basıncın arttırılması gereklidir, böylece Fonksiyonel Rezidüel Kapasite (Functional Residual Capacity-FRC)'nin normal sınırlarda kalması sağlanmış olur. FRC'nin normal sınırlarda kalmasını sağlamak çok önemlidir çünkü, rezidüel volüm ve total akciğer kapasitesindeki azalmalara $\mathrm{PaO}_{2}$ ve $\mathrm{PaCO}_{2}$ 'de değişimler de eklendiğinde atelektaziye sebep olabilirler. ${ }^{16}$ Akciğer volümlerini objektif ölçümlerle ortaya koymak için spirometrik incelemeler yapılabilir. Bu spirometrik incelemeler, uygulanacak fizyoterapi yöntemlerinin de karşılaştırılmasında oldukça önemlidir. ${ }^{17}$ Postoperatif erken dönemde kaybedilen akciğer volümleri ölçmek amacıyla biz de çalışmamızda solunum fonksiyon testlerini kullandık. Tam yüz maskesi veya sadece burun maskesi ile uygulanan CPAP azalan FRC'in arttırılmasında ve hipoksinin düzeltilmesinde etkili yöntemlerdir. Uygulanan fizyoterapi yöntemleri ile hastaların solunum fonksiyon testi parametrelerinde düzelmeler başladığı böylece postoperatif pulmoner komplikasyonların oluşmasını engellediği bildirilmiştir. ${ }^{13,14}$ Her iki hasta grubunda da postoperatif dokuzuncu güne gelindiğinde özellikle $\mathrm{FVC}, \mathrm{FEV}_{1}$ ve $\mathrm{FEF} \% 25-75$ değerlerinde istatistiksel olarak anlamlı volüm artışlarının başladığı gözlendi. Milles ve arkadaşlar ${ }^{18}$ bizim çalışmamıza benzer olarak majör torasik cerrahi geçiren hastalarda postoperatif pulmoner komplikasyonların önlenmesi için CPAP'1 hastalarına uygulamışlardır. Sonuç olarak oksijenasyonu arttırmada 5-10 $\mathrm{cmH}_{2} \mathrm{O}$ basıncın yeterli olabileceği sonucuna varmışlardır. Biz de çalışmamızda literatürle uyumlu olarak CPAP' $15 \mathrm{cmH}_{2} \mathrm{O}$ basınçla uyguladık ve sonuçta komplikasyon sayısının postoperatif dokuzuncu gündeki azalmasına dayanarak bu metodun etkili olduğu görüşündeyiz. Çalışmamızda literatürle uyumlu olarak postoperatif dokuzuncu günde komplikasyon sayılarında gözlenen azalma sonucunda her iki metodun da etkili olduğu görüşüne vardık. Ricksten ve arkadaşları ${ }^{19}$ üst abdominal cerrahi geçiren hastalarda postoperatif dönemde bir gruba CPAP, diğer gruba PEP uygularken, kontrol grubuna İS destekli derin solunum egzersizleri uygulamışlardır. Cerrahi sonrası, üç grupta da arterialalveolar oksijen farkında anlamlı bir artış görülürken, birinci gün bu artış maksimuma ulaşmıştır. Postoperatif ikinci gün, CPAP ve PEP grubunda arterial-alveolar oksijen farkı azalmış kontrol grubuyla karşılaştırıldığında ise PEP grubunda daha düşük olduğu gözlenmiştir. FVC değerinin CPAP ve PEP gruplarında kontrol grubuna göre daha yüksek olduğu görülmüştür. Atelektazi insidansı kontrol grubunda diğer gruplara göre daha yüksek çıkarken, CPAP ve PEP grupları arasında anlamlı bir fark gözlemlenmemiştir. Sonuçta CPAP ve PEP uygulanmasının, derin solunum egzersizlerine göre atelektazi oluşumunu engelleme ve akciğer hacimlerini arttırma açısından daha üstün olduğu sonucuna varmışlardır. Overend ve ark. ${ }^{20}$ yaptıkları bir derlemede taradıkları çalışmaların çoğunda kardiyak veya abdominal cerrahiyi takiben kullanılan İS'nin k1sa dönemde tedavi edici etkisinin olmadığını rapor etmişler ancak abdominal cerrahiyi takiben postoperatif 
pulmoner komplikasyonları önlemede İS'nin; derin nefes egzersizleri ve IPPB uygulanan hastalarda hiç tedavi görmeyen hastalara oranla aynı derecede etkili olduğu vurgulamışlardır. Kardiyak veya abdominal cerrahiyi takiben postoperatif komplikasyonların önlenmesinde İS uygulamalarının pozitif etkilerine dair yeterince kanıt olmadığı sonucuna varılmış ve daha fazla çalışmaya ihtiyaç olduğu belirtilmiştir. Bizim çalışmamızda postoperatif dokuzuncu günde SFT değerlerinde düzelme olmasında İS ve CPAP uygulamaları ile benzer sonuçlar alınmış olması ve İS'nin kolay uygulanabilir, ucuz bir yöntem olması nedeniyle postoperatif dönemde komplikasyonların önlenmesi için önerilebilir bir yöntem olduğu sonucuna varıldı.

Çalışmamızda hem İS grubu hem CPAP grubu hastalarımız postoperatif dokuzuncu gün solunum fonksiyon testi sonuçlarına göre uygulanan fizyoterapi çalışmalarından eşit miktarda fayda gördüler. Benzer olarak yapılan birçok çalışmada postoperatif fizyoterapinin etkinliği ve önemi üzerinde durulmuş, birçok yöntem kombine edilerek karşılaştırılmalar yapılmış ve fizyoterapi uygulamalarının olumlu etkileri sonuçlarda rapor edilmiştir. Bu uygulamaların birbirine üstünlük oluşturmadığı, sadece uygulanan maske yöntemlerinin derin solunum egzersizlerine üstünlük oluşturduğu bazı çalışmalar ile gösterilmiştir. $^{21,22}$ Varela ve arkadaşları ${ }^{23} 2006$ yılında yaptıkları bir çalışmada torasik cerrahi geçiren 119 hastaya İS, derin inspiratuar manevralar, statik bisiklet ve treadmil egzersizleri uygulamışlardır. 520 hastaya ise sadece rutin bakım ve İS uygulanmıştır. Bu çalışmada İS bir fizyoterapi yöntemi olarak değil hastalar tarafından bağımsız olarak fizyoterapi yerine kullanılmıştır. Fizyoterapi alan birinci grup hastalarda atelektazi insidansı $(\% 2-8)$ diğer gruba oranla düşük bulunmuştur $(\mathrm{p}<0.001)$. Fizyoterapi alan gurup hastaneden daha çabuk taburcu olduğu için maliyet açısında daha avantajlı olarak kabul edilmiştir. Braun ve arkadaşları ${ }^{24}$ akciğer volümlerinin ve devamlı akciğer difüzyon kapasitesinin koroner arter revaskülarizasyon ameliyatından sonra azaldığını bildirmişlerdir. Yine bu çalışmada uygulanan her iki teknik de akciğer volümlerini erken dönemde preoperatif seviyeye doğru geri döndürme konusunda birbirine üstün bulunmamıştır.

Çalışmamızda iki farklı mekanik fizyoterapi tekniği olan İS ve CPAP uygulanan gruplar arasında solunum fonksiyon testlerindeki değişimler açısından anlamlı bir fark görülmedi. Hastaların postoperatif solunum fonksiyon parametrelerindeki düşüşlerin düzeltilmesi için iki farklı fizyoterapi yönteminin birbirine üstünlüğü bulunamadı.

Bizim çalışmamızın limitasyonlarından biri FRC'nin ölçülememesidir. Bir diğer limitasyonu ise hasta gurubunun hem kardiyak hem de pulmoner cerrahi geçiren kişilerden oluşması yani homojen bir topluluk olmamasıdır.

Sonuç olarak; torasik cerrahi geçiren hastalarda solunum performansını geliştirmek ve dolayısıyla postoperatif pulmoner komplikasyonları önlemede mekanik fizyoterapi tekniklerinin etkili olduğu, hastaların postoperatif dönemde kaybetmiş oldukları akciğer volümlerini en kısa sürede kazanabilmelerinin önemli olduğu görüşündeyiz.

\section{Kaynaklar}

1. Ferguson MK. Preoperative assessment of pulmonary risk. Chest 1999;115: 58-63.

2. Hall JC, Talala RA, Mander J. A multivariate analysis of the risk of pulmonary complications after laparatomy. Chest 1991;99:923-7. 
3. Brooks JA, Brunn DNS. Predictors of postoperative pulmonary complications following abdominal surgery. Chest 1997;111:564-71.

4. Ferreyra G, Long Y, Ranieri VM. Respiratory complications after major surgery. Current Opinion in Critical Care 2009;15:342-8.

5. Stéphan F, Boucheseiche S, Hollande J, Flahault A, Cheffi A, Bazelly B, et al. Pulmonary complications following lung resection: a comprehensive analysis of incidence and possible risk factors. Chest 2000;118(5):1263-70.

6. Agostini P, Cieslik H, Rathinam S, Bishay E, Kalkat MS, Rajesh PB, et al. Postoperative pulmonary complications following thoracic surgery: are there any modifiable risk factors? Thorax 2010;65:815-8.

7. Eagle KA, Guyton RA, Davidiff R, Edwards FH, EwyGA, Fonger J, Gardner TJ, et al. ACC/AHA 2004 guideline update for coronary artery bypass graft surgery: Summary article. J Am Coll Cardio, 2004; 44:1146-54.

8. Berry CB, Butler PJ, Myles PS. Lung management during cardiopulmonary bypass: is continuous positive airways pressure beneficial? Br J Anaesth 1993;71(6):864-8.

9. Dyhr T, Laursen N, Larsson A. Effects of lung recruitment maneuver and positive endexpiratory pressure on lung volume, respiratory mechanics and alveolar gas mixing in patients ventilated after cardiac surgery. Acta Anaesthesiol Scand. 2002;46(6):717-25.

10. Allen MS, Darling GE, Pechet TT, Mitchell JD, Herndon JE, Landreneau RJ, et al; ACOSOG Z0030 Study Group. Morbidity and mortality of major pulmonary resections in patients with early-stage lung cancer: initial results of the randomized, prospective ACOSOG Z0030 trial. Ann Thorac Surg 2006;81:1013-20.

11. Garcia Miguel FJ, Serrano-Aguilar PG, Lopez-Bastida J. Preoperative assessment. Lancet 2003;362:1749-59.

12. Patel RL, Townsend ER, Fountain SW. Elective pneumonectomy: factors associated with morbidity and operative mortality. Ann Thorac Surg 1992; 54:84-8.

13. Renault JA, Costa-Val R, Rossetti MB. Respiratory physiotherapy in the pulmonary dysfunction after cardiac surgery. Rev Bras Cir Cardiovasc 2008;23:562-9.

14. Savci S, Sakin S, Inal Ince D, Arikan H, Can Z, Buran Y, Kuralay E. Active cycle of breathing techniques and incentive spirometer in coronary artery bypass graft surgery. Fizyoterapi Rehabilitasyon 2006;17:61-9.

15. Brooks D, Crowe J, Kelsey CJ, Lacy JB, Parsons J, Solway S. A clinical practice guideline on peri-operative cardiorespiratory physical therapy. Physiotherapy Canada 2001;53(1):9-25.

16. Tusman G, Bohm SH, Tempra A, Melkun F, Garcia E, Turchetto E, Mulder PG, Lachmann B: Effects of recruitment maneuver on atelectasis in anesthetized children. Anesthesiology 2003; 98:14-22

17.Berrizbeitia LD, Tessler S, Jacobowitz IJ,et al. Effect of sternotomy and coronary bypass surgery on postoperative pulmonary mechanics: Comparison of internal mammary and saphenous vein bypass grafts. Chest 1989:96;873-6. 
18. Kindgen-Milles D, Buhl R, Gabriel A, Böhner H and Müler. Nasal Continuous Positive Airway Pressure A Method to Avoid Endotracheal Reintubation in Postoperative High-risk Patients With Severe Nonhypercapnic Oxygenation Failure. Chest 2000;117:1106-11.

19. Ricksten SE, Bengtsson A, Soderberg C, Thorden M, Kvist H. Effects of periodic positive airway pressure by mask on postoperative pulmonary function. Chest 1986;89: 774-81.

20.Overend T J, Anderson MA, Lucy SD, Bhatia C,Jonsson BI, Timmermans C. The Effect of Incentive Spirometry on Postoperative Pulmonary Complications.A Systematic Review. Chest 2001;120(3):971-8.

21. Gürses HN. Peroperatif rehabilitasyon, Kronik solunum yetersizliğinde solunum pompa desteği. Solunum 2002;4: 332-8.

22. Sarkıç S. Açık kalp ameliyatı geçiren hastalarda İnsentif Spirometre ile aktif solunum teknikleri döngüsünün etkinliğinin karşılaştırılması. Kardiyopulmoner Rehabilitasyon programı yüksek lisans tezi, Hacettepe Üniversitesi Sağlık Bilimleri Enstitüsü, Ankara, 2004.

23. Varela G, Ballesteros E, Jimenez MF, Novoa N, Aranda JL. Cost effectiveness analysis of prophylactic respiratory physiotherapy in pulmonary lobectomy. Eur $J$ Cardiothorac Surg 2006;29:216-20.

24. Braun SR, Brinbaum ML, ChoprA PS. Pre and postoperative pulmonary function abnormalities in coronary artery revascularization surgey. Chest 1978;73:316-20. 